\title{
A study of substituent effect on the oxidative strengths of sodium salts of N-bromo-arylsulphonamides: Kinetics and mechanism of oxidation of D-fructose and D-glucose in alkaline medium
}

\author{
K M USHA and B THIMME GOWDA* \\ Department of Post-Graduate Studies and Research in Chemistry, Mangalore University, \\ Mangalagangothri, Mangalore 574199 \\ e-mail: gowdabt@yahoo.com
}

MS received 13 July 2005; revised 13 March 2006

\begin{abstract}
N-Bromo-arylsulphonamides of different oxidizing strengths are used for studying the kinetics of oxidation of D-fructose and D-glucose in aqueous alkaline medium. The results are analysed and compared with those from the sodium salts of N-bromo-benzenesulphonamide and N-bromo-4-methylbenzenesulphonamide. The reactions show zero-order kinetics in [oxidant], fractional order in [Fru/Glu] and nearly first order in $\left[\mathrm{OH}^{-}\right]$. Rates of oxidation of fructose are higher than those for glucose with the same oxidant. Similarly, $E_{a}$ values for glucose oxidations are higher than those for fructose. The results are explained by a suitable mechanism and the related rate law is deduced. The effective oxidising species in the reactions of $\mathrm{N}$-bromo-arylsulphonamides is $\mathrm{Br}^{+}$. The oxidative strengths of the latter therefore depend on the ease with which $\mathrm{Br}^{+}$is released from them. The ease with which $\mathrm{Br}^{+}$is released from $\mathrm{N}$ bromo-arylsulphonamides depends on the electron density on the nitrogen atom of the sulphonamide group, which in turn depends on the nature of the substituent on the benzene ring. The validity of the Hammett equation has also been tested for oxidation of both fructose and glucose. Enthalpies and entropies of activations of the oxidations by all the N-bromo-arylsulphonamides correlate well. The effect of substitution on $E_{a}$ and $\log A$ of the oxidations is also considered.
\end{abstract}

Keywords. Kinetics of oxidation; N-bromo-arylsulphonamides; D-fructose, D-glucose.

\section{Introduction}

$\mathrm{N}$-Haloarylsulphonamides act as halonium cations, hypohalite species and $\mathrm{N}$-anions which behave both as bases and nucleophiles. Due to these diverse properties they have received considerable attention. ${ }^{1-3}$ Although the various aspects of the prominent members of this class of reagents, known as bromamine-B and bromamine-T, have been studied, there have been no efforts to produce N-bromo-arylsulphonamide of the required oxidising strength for a specific purpose. Hence, in an effort to introduce Nbromo-arylsulphonamides of different oxidizing strengths, we have recently reported the synthetic, infrared and NMR $\left({ }^{1} \mathrm{H}\right.$ and $\left.{ }^{13} \mathrm{C}\right)$ spectral studies of fifteen sodium salts of N-bromo-substituted benzenesulphonamides (NBSBS) of the general formulae, 4$\mathrm{X}-\mathrm{C}_{6} \mathrm{H}_{4} \mathrm{SO}_{2} \mathrm{NaNBr} \cdot \mathrm{H}_{2} \mathrm{O}\left(\mathrm{X}=\mathrm{H} ; \mathrm{CH}_{3} ; \mathrm{C}_{2} \mathrm{H}_{5} ; \mathrm{F} ; \mathrm{Cl}\right.$; $\mathrm{Br}$ or $\left.\mathrm{NO}_{2}\right)$ and $i-\mathrm{X}-j-\mathrm{Y}-\mathrm{C}_{6} \mathrm{H}_{3} \mathrm{SO}_{2} \mathrm{NaNBr} . \mathrm{H}_{2} \mathrm{O}(i-\mathrm{X}-j-$

\footnotetext{
*For correspondence
}

$\mathrm{Y}=2,3-\left(\mathrm{CH}_{3}\right)_{2} ; 2,4-\left(\mathrm{CH}_{3}\right)_{2} ; 2,5-\left(\mathrm{CH}_{3}\right)_{2} ; 2-\mathrm{CH}_{3}-4-\mathrm{Cl} ;$ $2-\mathrm{CH}_{3}-5-\mathrm{Cl} ; \quad 3-\mathrm{CH}_{3}-4-\mathrm{Cl} ; \quad 2,4-\mathrm{Cl}_{2}$ or $\left.3,4-\mathrm{Cl}_{2}\right)$. ${ }^{2 \mathrm{~m}}$ Here, sodium salts of N-bromo-4-ethylbenzenesulphonamide (NB4EBS), N-bromo-4-fluorobenzenesulphonamide (NB4FBS), N-bromo-4-chlorobenzenesulphonamide (NB4CBS), N-bromo-4-bromobenzenesulphonamide (NB4BBS), have been employed as oxidants for studying the kinetics of oxidation of D-fructose and D-glucose in aqueous alkaline medium. The results have been analysed along with those by the sodium salts of N-bromo-benzenesulphonamide (NBBS, bromamine-B) and N-bromo-4methylbenzenesulphonamide (NB4MBS, bromamineT) ${ }^{4,5} \mathrm{In}$ fact, the kinetics of oxidation of D-fructose and D-glucose by these oxidants have also been carried out under identical conditions and analysed.

Carbohydrates comprise one of the largest classes of biologically important compounds and are characterised by the presence of an aldehydic or ketonic carbonyl group..$^{6-9}$ Monosaccharides such as glucose and fructose have wide synthetic applications. Glu- 
cose is a source of energy in plants and animals and also serves as the monomeric unit of cellulose, the structural framework in woody plants. Hence, the reactions involving carbohydrates are of considerable interest.

\section{Materials and methods}

All the substituted-N-bromobenzenesulphonamides (NBSBS) were prepared in good purity by the procedures described elsewhere. ${ }^{2 \mathrm{~m}}$ Aqueous stock solutions of these compounds $\left(0.01 \mathrm{~mol} \mathrm{dm}^{-3}\right)$ were prepared in doubly distilled water, standardised by the iodometric method and stored in dark-coloured bottles to prevent their photochemical deteriorations. Analytical grade samples of D-fructose and D-glucose (Glu) (E. Merck) were employed. Fresh solutions in doubly distilled water $\left(0 \cdot 10 \mathrm{~mol} \mathrm{dm}^{-3}\right)$ were prepared as and when required. All other reagents employed were of analytical grade. Ionic strength of the medium was maintained at $0.30 \mathrm{~mol} \mathrm{dm}^{-3}$ using concentrated aqueous solution of sodium nitrate.

\section{$2.1 \quad$ Kinetic measurements}

Kinetic studies were carried out in glass-stoppered pyrex boiling tubes under pseudo-first order conditions with [Fru or Glu] > [NBSBS] (by 5-50 times). The reactions were initiated by the rapid addition of known amounts of oxidant solution (0.0005$0.004 \mathrm{~mol} \mathrm{dm}^{-3}$ ), pre-equilibrated at a desired temperature, to mixtures containing the required amounts of substrates $\left(0 \cdot 005-0.05 \mathrm{~mol} \mathrm{dm}^{-3}\right)$, sodium hydroxide $\left(0 \cdot 005-0.5 \mathrm{~mol} \mathrm{dm} \mathrm{dm}^{-3}\right)$, sodium nitrate and water in the boiling tube, thermostatted at the same temperature. Progress of the reactions was monitored for at least two half-lives by the iodometric determination of unreacted oxidant at regular intervals of time. Pseudo-zero order rate constants $\left(k_{\mathrm{obs}}\right)$ were computed by graphical methods and the values are reproducible within $\pm 4 \%$ error.

\subsection{Stoichiometry and product analysis}

The reaction mixture containing the sugar, $\mathrm{NaOH}$ and excess of NBSBS was equilibrated for $24 \mathrm{~h}$ and then the excess of oxidant was determined iodometrically. Varying stoichiometries were observed corresponding to the formation of a mixture of products as shown by the following stoichiometric equations.
The major products of oxidations were arabinonic, ribonic and erythronic acids, while the minor products were glyceric and hexonic acids.

$$
\begin{aligned}
& \mathrm{C}_{6} \mathrm{H}_{12} \mathrm{O}_{6}+\mathrm{ArSO}_{2} \mathrm{NBr}^{-}+\mathrm{H}_{2} \mathrm{O}+\mathrm{OH}^{-} \rightarrow \\
& \mathrm{C}_{5} \mathrm{H}_{10} \mathrm{O}_{6}+\mathrm{CH}_{2}(\mathrm{OH})_{2}+\mathrm{ArSO}_{2} \mathrm{NH}^{-}+\mathrm{Br}^{-}, \\
& \text {(arabinonic or ribonic acids) }
\end{aligned}
$$

$$
\begin{aligned}
& \mathrm{C}_{6} \mathrm{H}_{12} \mathrm{O}_{6}+2 \mathrm{ArSO}_{2} \mathrm{NBr}^{-}+3 \mathrm{OH}^{-} \rightarrow \mathrm{C}_{4} \mathrm{H}_{8} \mathrm{O}_{5} \\
& +\mathrm{CH}_{2}(\mathrm{OH}) \mathrm{COO}^{-}+2 \mathrm{ArSO}_{2} \mathrm{NH}^{-}+2 \mathrm{Br}^{-}+\mathrm{H}_{2} \mathrm{O}, \\
& \text { erythronic acid }
\end{aligned}
$$

$$
\begin{aligned}
& \mathrm{C}_{6} \mathrm{H}_{12} \mathrm{O}_{6}+3 \mathrm{ArSO}_{2} \mathrm{NBr}^{-}+5 \mathrm{OH}^{-} \rightarrow \\
& \mathrm{C}_{3} \mathrm{H}_{6} \mathrm{O}_{4}+\mathrm{CH}_{2}(\mathrm{OH}) \mathrm{COO}^{-}+\mathrm{HCOO}^{-}+ \\
& \text {Glyceric acid } 3 \mathrm{ArSO}_{2} \mathrm{NH}^{-}+3 \mathrm{Br}^{-}+2 \mathrm{H}_{2} \mathrm{O},
\end{aligned}
$$

$$
\begin{aligned}
\mathrm{C}_{6} \mathrm{H}_{12} \mathrm{O}_{6}+\underset{\mathrm{ArSO}_{2} \mathrm{NBr}^{-}+\mathrm{OH}^{-} \rightarrow}{\mathrm{C}_{6} \mathrm{H}_{12} \mathrm{O}_{7}+\mathrm{ArSO}_{2} \mathrm{NH}^{-}+\mathrm{Br}^{-},} \\
\text {Hexonic acid }
\end{aligned}
$$

where $\mathrm{Ar}=\mathrm{C}_{6} \mathrm{H}_{5}, 4-\mathrm{CH}_{3} \mathrm{C}_{6} \mathrm{H}_{4}, 4-\mathrm{C}_{2} \mathrm{H}_{5} \mathrm{C}_{6} \mathrm{H}_{4}, 4-\mathrm{FC}_{6} \mathrm{H}_{4}$, 4- $\mathrm{ClC}_{6} \mathrm{H}_{4}$ or $4-\mathrm{BrC}_{6} \mathrm{H}_{4}$.

The reduction products, arylsulphonamides (SBSA), were identified by TLC $^{10}$ using petroleum etherchloroform-butanol $(2: 2: 1 \mathrm{v} / \mathrm{v})$ as the solvent system and iodine as spray reagent. $R_{f}$ values of the reduced arylsulphonamides compared with those of the pure sulphonamides (values in parentheses) were 0.93 (0.94), $0.90(0.92), 0.91(0.93)$ and $0.88(0.89)$ for 4-ethyl-, 4-fluoro-, 4-chloro- and 4-bromo-benzenesulphonamides, respectively.

\section{Results}

Kinetic data on the oxidation of D-fructose and Dglucose by the six oxidants in aqueous alkaline medium under varying conditions of [NBSBS], $[\mathrm{Fru} / \mathrm{Glu}],[\mathrm{NaOH}]$ and ionic strength of the medium are shown in tables 1 and 2.

\subsection{Effect of varying [NBSBS $\left.]_{0}\right]$}

At constant [Fru or Glu $]_{0}$ (5-50 fold excess over $\left.[\mathrm{NBSBS}]_{0}\right)$ and $\left[\mathrm{OH}^{-}\right]$, the zero order plots of [NBSBS] versus time were linear up to at least $75 \%$ completion of the reactions. The pseudo-zero order rate constants computed from the plots remained unaffected by the changes in [NBSBS $]_{0}$ (tables 1 and 2 ), establishing zero order dependence of the rate on [NBSBS] for all the oxidations. 
Table 1. Pseudo zero-order rate constants $\left(k_{\text {obs }}\right)$ for the oxidation of D-fructose (Fru) by the sodium salts of N-bromo$p$-substituted benzenesulphonamides (NBSBS) in aqueous alkaline medium at $293 \mathrm{~K}\left(I=0 \cdot 3 \mathrm{~mol} \mathrm{dm}^{-3} \mathrm{except}^{\mathrm{during}}\right.$ its variation).

\begin{tabular}{|c|c|c|c|c|c|c|c|c|}
\hline \multirow{2}{*}{$\begin{array}{l}10^{3}[\mathrm{NBSBS}]_{0} \\
\mathrm{~mol} \mathrm{dm}^{-3}\end{array}$} & \multirow{2}{*}{$\begin{array}{l}10^{2}[\mathrm{Fru}]_{0} \\
\mathrm{~mol} \mathrm{dm}^{-3}\end{array}$} & \multirow{2}{*}{$\begin{array}{l}10^{2}\left[\mathrm{OH}^{-}\right] \\
\mathrm{mol} \mathrm{dm}^{-3}\end{array}$} & \multicolumn{6}{|c|}{$\begin{array}{c}10^{7} k_{\mathrm{obs}}\left(\mathrm{dm}^{3} \mathrm{~mol}^{-} \mathrm{s}^{-1}\right) \\
i-\mathrm{X}-\mathrm{C}_{6} \mathrm{H}_{4} \mathrm{SO}_{2}(\mathrm{Na}) \mathrm{NBr} \cdot x \mathrm{H}_{2} \mathrm{O}, i-\mathrm{X}=\end{array}$} \\
\hline & & & Parent & $4-\mathrm{CH}_{3}$ & $4-\mathrm{C}_{2} \mathrm{H}_{5}$ & $4-F$ & $4-\mathrm{Cl}$ & $4-\mathrm{Br}$ \\
\hline \multicolumn{9}{|c|}{ Effect of varying $[N B S B S]_{0}$} \\
\hline $0 \cdot 5$ & $2 \cdot 0$ & $1 \cdot 0$ & $3 \cdot 1$ & $2 \cdot 6$ & $3 \cdot 5$ & $3 \cdot 3$ & $4 \cdot 1$ & $3 \cdot 8$ \\
\hline $1 \cdot 0$ & $2 \cdot 0$ & $1 \cdot 0$ & $3 \cdot 1$ & $2 \cdot 6$ & $3 \cdot 5$ & $3 \cdot 3$ & $4 \cdot 1$ & $3 \cdot 8$ \\
\hline $2 \cdot 0$ & $2 \cdot 0$ & $1 \cdot 0$ & $3 \cdot 3$ & $2 \cdot 5$ & $3 \cdot 3$ & $3 \cdot 5$ & $4 \cdot 0$ & $3 \cdot 5$ \\
\hline $4 \cdot 0$ & $2 \cdot 0$ & $1 \cdot 0$ & $3 \cdot 5$ & $2 \cdot 3$ & $3 \cdot 1$ & $3 \cdot 1$ & $4 \cdot 0$ & $3 \cdot 5$ \\
\hline $1 \cdot 0^{\mathrm{a}}$ & $2 \cdot 0$ & $1 \cdot 0$ & $3 \cdot 1$ & $2 \cdot 6$ & $3 \cdot 3$ & $3 \cdot 3$ & $4 \cdot 0$ & $3 \cdot 8$ \\
\hline $1 \cdot 0^{\mathrm{b}}$ & $2 \cdot 0$ & $1 \cdot 0$ & $3 \cdot 5$ & $2 \cdot 8$ & $3 \cdot 5$ & $3 \cdot 5$ & $4 \cdot 1$ & $3 \cdot 8$ \\
\hline \multicolumn{9}{|c|}{ Effect of varying $[\mathrm{Fru}]_{0}$} \\
\hline 1.0 & 0.5 & $1 \cdot 0$ & $1 \cdot 1$ & $0 \cdot 8$ & $1 \cdot 5$ & $1 \cdot 3$ & $1 \cdot 8$ & $1 \cdot 5$ \\
\hline $1 \cdot 0$ & $1 \cdot 0$ & $1 \cdot 0$ & $1 \cdot 8$ & $1 \cdot 6$ & $2 \cdot 5$ & $2 \cdot 3$ & $3 \cdot 0$ & $2 \cdot 3$ \\
\hline $1 \cdot 0$ & $2 \cdot 0$ & $1 \cdot 0$ & $3 \cdot 1$ & $2 \cdot 6$ & $3 \cdot 5$ & $3 \cdot 3$ & $4 \cdot 1$ & $3 \cdot 8$ \\
\hline $1 \cdot 0$ & $3 \cdot 0$ & $1 \cdot 0$ & - & $5 \cdot 6$ & $4 \cdot 3$ & $4 \cdot 5$ & $6 \cdot 0$ & $5 \cdot 1$ \\
\hline $1 \cdot 0$ & $5 \cdot 0$ & $1 \cdot 0$ & $7 \cdot 8$ & $7 \cdot 5$ & $5 \cdot 2$ & $6 \cdot 6$ & $6 \cdot 8$ & $7 \cdot 8$ \\
\hline \multicolumn{9}{|c|}{ Effect of varying $\left[\mathrm{OH}^{-}\right]$} \\
\hline $1 \cdot 0$ & $2 \cdot 0$ & $0 \cdot 5$ & $1 \cdot 5$ & $1 \cdot 1$ & $1 \cdot 5$ & $1 \cdot 3$ & $1 \cdot 5$ & $2 \cdot 0$ \\
\hline $1 \cdot 0$ & $2 \cdot 0$ & $1 \cdot 0$ & $3 \cdot 1$ & $2 \cdot 6$ & $3 \cdot 5$ & $3 \cdot 3$ & $4 \cdot 1$ & $3 \cdot 8$ \\
\hline $1 \cdot 0$ & $2 \cdot 0$ & $2 \cdot 0$ & $6 \cdot 5$ & $5 \cdot 6$ & $6 \cdot 3$ & $7 \cdot 0$ & $6 \cdot 6$ & $6 \cdot 1$ \\
\hline $1 \cdot 0$ & $2 \cdot 0$ & $3 \cdot 0$ & $9 \cdot 0$ & $8 \cdot 8$ & $9 \cdot 8$ & $11 \cdot 0$ & $10 \cdot 1$ & $11 \cdot 3$ \\
\hline $1 \cdot 0$ & $2 \cdot 0$ & $4 \cdot 0$ & $12 \cdot 1$ & $10 \cdot 6$ & $12 \cdot 8$ & $13 \cdot 1$ & $14 \cdot 0$ & $14 \cdot 0$ \\
\hline $1 \cdot 0$ & $2 \cdot 0$ & $5 \cdot 0$ & $13 \cdot 7$ & $11 \cdot 6$ & $13 \cdot 2$ & 14.0 & $15 \cdot 3$ & $15 \cdot 0$ \\
\hline
\end{tabular}

$I\left(\mathrm{~mol} \mathrm{dm}^{-3}\right)=0 \cdot 10(\mathrm{a}), 0 \cdot 50(\mathrm{~b})$

Table 2. Pseudo zero-order rate constants $\left(k_{\mathrm{obs}}\right)$ for the oxidation of D-glucose (Glu) by the sodium salts of N-bromo$p$-substituted benzenesulphonamides (NBSBS) in aqueous alkaline medium at $303 \mathrm{~K}\left(I=0 \cdot 3 \mathrm{~mol} \mathrm{dm}^{-3} \mathrm{except}^{\mathrm{during}}\right.$ its variation).

\begin{tabular}{|c|c|c|c|c|c|c|c|c|}
\hline \multirow{2}{*}{$\begin{array}{l}10^{3}[\mathrm{NBSBS}]_{\mathrm{o}} \\
\mathrm{mol} \mathrm{dm}^{-3}\end{array}$} & \multirow{2}{*}{$\begin{array}{l}10^{2}[\mathrm{Glu}]_{\mathrm{o}} \\
\mathrm{mol} \mathrm{dm}^{-3}\end{array}$} & \multirow{2}{*}{$\begin{array}{l}10^{2}\left[\mathrm{OH}^{-}\right] \\
\mathrm{mol} \mathrm{dm}^{-3}\end{array}$} & \multicolumn{6}{|c|}{$\begin{array}{c}10^{7} k_{\text {obs }}\left(\mathrm{dm}^{3} \mathrm{~mol}^{-1} \mathrm{~s}^{-1}\right) \\
i-\mathrm{X}-\mathrm{C}_{6} \mathrm{H}_{4} \mathrm{SO}_{2}(\mathrm{Na}) \mathrm{NBr} \cdot x \mathrm{H}_{2} \mathrm{O}, i-\mathrm{X}=\end{array}$} \\
\hline & & & Parent & $4-\mathrm{CH}_{3}$ & $4-\mathrm{C}_{2} \mathrm{H}_{5}$ & $4-F$ & $4-\mathrm{Cl}$ & $4-\mathrm{Br}$ \\
\hline \multicolumn{9}{|c|}{ Effect of varying $[N B S B S]_{0}$} \\
\hline 0.5 & $2 \cdot 0$ & $1 \cdot 0$ & $2 \cdot 8$ & $2 \cdot 6$ & $2 \cdot 3$ & $2 \cdot 6$ & $3 \cdot 3$ & $3 \cdot 0$ \\
\hline $1 \cdot 0$ & $2 \cdot 0$ & $1 \cdot 0$ & $2 \cdot 8$ & $2 \cdot 6$ & $2 \cdot 3$ & $2 \cdot 5$ & $3 \cdot 0$ & $3 \cdot 0$ \\
\hline $2 \cdot 0$ & $2 \cdot 0$ & $1 \cdot 0$ & $2 \cdot 8$ & $2 \cdot 5$ & $2 \cdot 2$ & $2 \cdot 4$ & $3 \cdot 0$ & $2 \cdot 8$ \\
\hline $4 \cdot 0$ & $2 \cdot 0$ & $1 \cdot 0$ & $2 \cdot 6$ & $2 \cdot 3$ & $2 \cdot 3$ & $2 \cdot 6$ & $2 \cdot 8$ & $2 \cdot 8$ \\
\hline $1 \cdot 0^{\mathrm{a}}$ & $2 \cdot 0$ & $1 \cdot 0$ & $2 \cdot 8$ & $2 \cdot 6$ & $2 \cdot 3$ & $2 \cdot 5$ & $3 \cdot 0$ & $2 \cdot 8$ \\
\hline $1 \cdot 0^{\mathrm{b}}$ & $2 \cdot 0$ & $1 \cdot 0$ & $3 \cdot 0$ & $2 \cdot 8$ & $2 \cdot 5$ & $2 \cdot 4$ & $2 \cdot 8$ & $3 \cdot 1$ \\
\hline \multicolumn{9}{|c|}{ Effect of varying $[G l u]_{0}$} \\
\hline 1.0 & $0 \cdot 5$ & $1 \cdot 0$ & $1 \cdot 2$ & $0 \cdot 8$ & $1 \cdot 1$ & $1 \cdot 0$ & $1 \cdot 1$ & $1 \cdot 3$ \\
\hline $1 \cdot 0$ & $1 \cdot 0$ & $1 \cdot 0$ & $2 \cdot 0$ & $1 \cdot 7$ & $1 \cdot 8$ & $2 \cdot 0$ & $1 \cdot 7$ & $2 \cdot 0$ \\
\hline $1 \cdot 0$ & $2 \cdot 0$ & $1 \cdot 0$ & $2 \cdot 8$ & $2 \cdot 6$ & $2 \cdot 3$ & $2 \cdot 5$ & $3 \cdot 0$ & $3 \cdot 0$ \\
\hline $1 \cdot 0$ & $3 \cdot 0$ & $1 \cdot 0$ & - & - & $3 \cdot 0$ & $3 \cdot 3$ & $4 \cdot 1$ & $3 \cdot 5$ \\
\hline $1 \cdot 0$ & $5 \cdot 0$ & $1 \cdot 0$ & $4 \cdot 5$ & $3 \cdot 7$ & $3 \cdot 7$ & $4 \cdot 5$ & $5 \cdot 5$ & $4 \cdot 7$ \\
\hline \multicolumn{9}{|c|}{ Effect of varying $\left[\mathrm{OH}^{-}\right]$} \\
\hline $1 \cdot 0$ & $2 \cdot 0$ & $0 \cdot 5$ & $1 \cdot 2$ & $1 \cdot 3$ & $0 \cdot 7$ & $1 \cdot 2$ & $1 \cdot 2$ & $1 \cdot 2$ \\
\hline $1 \cdot 0$ & $2 \cdot 0$ & $1 \cdot 0$ & $2 \cdot 8$ & $2 \cdot 6$ & $2 \cdot 3$ & $2 \cdot 5$ & $3 \cdot 0$ & $3 \cdot 0$ \\
\hline $1 \cdot 0$ & $2 \cdot 0$ & $2 \cdot 0$ & $5 \cdot 7$ & $6 \cdot 0$ & $6 \cdot 0$ & $5 \cdot 3$ & $5 \cdot 5$ & $5 \cdot 6$ \\
\hline $1 \cdot 0$ & $2 \cdot 0$ & $3 \cdot 0$ & - & $9 \cdot 6$ & $7 \cdot 8$ & $10 \cdot 5$ & $9 \cdot 2$ & $8 \cdot 7$ \\
\hline $1 \cdot 0$ & $2 \cdot 0$ & $4 \cdot 0$ & $11 \cdot 6$ & $10 \cdot 3$ & $8 \cdot 3$ & $11 \cdot 7$ & $12 \cdot 1$ & $13 \cdot 0$ \\
\hline $1 \cdot 0$ & $2 \cdot 0$ & $5 \cdot 0$ & $13 \cdot 8$ & $10 \cdot 9$ & $9 \cdot 7$ & $14 \cdot 6$ & $14 \cdot 1$ & $15 \cdot 0$ \\
\hline
\end{tabular}

$I\left(\mathrm{~mol} \mathrm{dm}^{-3}\right)=0 \cdot 10(\mathrm{a}), 0 \cdot 50(\mathrm{~b})$ 
3.2 Effect of varying [Fru or Glu $]_{0},\left[\mathrm{OH}^{-}\right]$and other parameters of the medium

At constant $[\mathrm{NBSBS}]_{0}$ and $\left[\mathrm{OH}^{-}\right]$, the rates increased with increase in $[\mathrm{Fru} / \mathrm{Glu}]_{0}$, with fractional order dependences in all the cases (tables 1 and 2). Plots of $1 / k_{\text {obs }}$ versus $1 /[\mathrm{Fru} / \mathrm{Glu}]_{0}$ gave straight lines with finite intercepts on the ordinates. At constant $[\mathrm{NBSBS}]_{0}$ and $[\mathrm{Fru} / \mathrm{Glu}]_{0}$, the rates increased with increase in $\left[\mathrm{OH}^{-}\right]$with nearly first-order dependences on $\left[\mathrm{OH}^{-}\right]$ (tables 1 and 2) for all the oxidations. At constant $[\mathrm{NBSBS}]_{0},[\mathrm{Fru} / \mathrm{Glu}]_{0}$ and $\left[\mathrm{OH}^{-}\right]$, increase in ionic strength of the medium had little effect on the rates (tables 1 and 2). The rates were measured at different temperatures $(288-313 \mathrm{~K})$ for the oxidation of both the substrates by all the oxidants and the activation parameters were computed from the Arrhenius and Eyring plots as described later.

\section{Discussion - mechanism of oxidation}

Sodium salts of N-bromo-substitutedbenzenesulphonamides (NBSBS) are fairly strong electrolytes in aqueous solution. They furnish different reactive species depending on the $\mathrm{pH}$ of the medium. The possible oxidising species in alkaline solutions of NBSBS are $\mathrm{ArSO}_{2} \mathrm{NBr}^{-}, \mathrm{ArSO}_{2} \mathrm{NHBr}, \mathrm{OBr}^{-}$and $\mathrm{ArSO}_{2} \mathrm{NBr}_{2}$, depending on $\left[\mathrm{OH}^{-}\right]$, (where $\mathrm{Ar}=\mathrm{C}_{6} \mathrm{H}_{5}$, $4-\mathrm{CH}_{3} \mathrm{C}_{6} \mathrm{H}_{4}, 4-\mathrm{C}_{2} \mathrm{H}_{5} \mathrm{C}_{6} \mathrm{H}_{4}, 4-\mathrm{FC}_{6} \mathrm{H}_{4}, 4-\mathrm{ClC}_{6} \mathrm{H}_{4}$ or 4$\mathrm{BrC}_{6} \mathrm{H}_{4}$ ).

$$
\begin{aligned}
& \mathrm{ArSO}_{2} \mathrm{NBr}^{-}+\mathrm{H}_{2} \mathrm{O} \rightleftharpoons \mathrm{ArSO}_{2} \mathrm{NH}_{2}+\mathrm{OBr}^{-} \\
& \mathrm{ArSO}_{2} \mathrm{NBr}^{-}+\mathrm{H}_{2} \mathrm{O} \rightleftharpoons \mathrm{ArSO}_{2} \mathrm{NHBr}+\mathrm{HO}^{-}, \\
& \mathrm{ArSO}_{2} \mathrm{NHBr}+\mathrm{HO}^{-} \rightleftharpoons \mathrm{ArSO}_{2} \mathrm{NH}_{2}+\mathrm{OBr}^{-}
\end{aligned}
$$

Reactions (5) and (7) predict retardation of rates by the reaction products, arylsulphonamides, while (6) expects retardation of rates by $\mathrm{OH}^{-}$ions. Since the rate increases with increase in $\mathrm{OH}^{-}$and is not affected by the addition of sulphonamides, it is likely that the anion $\mathrm{OBr}^{-}$is the active oxidising species. This is supported by the fact that substitution in the benzene ring had little effect on the oxidation of both the substrates.

In alkaline solutions, sugars undergo isomerisation to an equilibrium mixture of aldoses and ketoses which exist as enediol anions $(E)$. In the presence of oxidants, the enolic anions react with $\mathrm{OBr}^{-}$or $\mathrm{ArSO}_{2} \mathrm{NBr}^{-}$to form the intermediates, which subse- quently undergo cleavages to form the products. It has been shown that hexoses react with the oxidants through keto-enolic anion intermediates. It has been further shown that hexoses react very slowly in the aldo-enolic forms. ${ }^{9}$ Fructose has a more orderly structure than glucose. It is thus sterically favoured for oxidation by the oxidants as has been noticed earlier. ${ }^{11}$ Therefore, it is probable that in the case of glucose, the fructose isomer formed by the alkalicatalysed isomerisation reacts with the oxidants. This observation is supported by the fact that the rates with fructose were higher than those with glucose for the same oxidant. Similarly, the $E_{a}$ values are higher for glucose compared with $E_{a}$ values for fructose. In other words, higher rates and lower $E_{a}$ with fructose and lower rates and higher $E_{a}$ with glucose support these observations.

Based on these facts, the observed kinetics of zero order in [NBSBS], nearly first order in $\left[\mathrm{OH}^{-}\right]$and fractional order in [S], negligible ionic strength and product effects for the oxidations of both the carbohydrates by N-bromobenzenesulphonamides have been explained through the reaction sequences shown in scheme 1.

$$
\begin{aligned}
& \mathrm{S}+\mathrm{OH}^{-} \stackrel{K_{1}}{\rightleftharpoons} \mathrm{X}, \\
& \mathrm{X} \stackrel{k_{2}}{\rightarrow} \mathrm{E}^{-}+\mathrm{H}_{2} \mathrm{O}, \\
& \mathrm{E}^{-}+\mathrm{OBr}^{-} \rightarrow \mathrm{X}^{\prime}, \\
& \mathrm{X}^{\prime}+\mathrm{H}_{2} \mathrm{O} / \mathrm{OH}^{-} \rightarrow \text { products, }
\end{aligned}
$$

where S (substrate): Fru/Glu.

\section{Scheme 1.}

The rate laws in accordance with scheme 1 are given by

$$
\begin{aligned}
& k_{\mathrm{obs}}=\frac{K_{1} k_{2}[\mathrm{~S}]\left[\mathrm{OH}^{-}\right]}{1+K_{1}\left[\mathrm{OH}^{-}\right]+K_{1}[\mathrm{~S}]}, \\
& \frac{1}{k_{\mathrm{obs}}}=\frac{1+K_{1}\left[\mathrm{OH}^{-}\right]}{K_{1} k_{2}\left[\mathrm{OH}^{-}\right]} \frac{1}{[\mathrm{~S}]}+\frac{1}{k_{2}\left[\mathrm{OH}^{-}\right]} .
\end{aligned}
$$

The plots of $1 / k_{\mathrm{obs}}$ verses $1 /[\mathrm{Fru} / \mathrm{Glu}]_{0}$ were linear in conformity with the rate law (13). The constant $k_{2}$ 
Table 3. The calculated constants at different temperatures of the rate determining $\left(k_{2}\right)$ and pre-equilibrium $\left(K_{1}\right)$ steps of the mechanism for the oxidation of D-fructose and $\mathrm{D}$-glucose by sodium salts of N-bromo- $p$-substituted benzenesulphonamides, $i$-X$\mathrm{C}_{6} \mathrm{H}_{4} \mathrm{SO}_{2} \mathrm{NaNBr} \cdot \mathrm{H}_{2} \mathrm{O}$, in aqueous alkaline medium.

\begin{tabular}{|c|c|c|c|c|c|c|c|}
\hline & \multirow[b]{2}{*}{ Temperature (K) } & \multicolumn{5}{|c|}{$10^{7} k_{2}\left(\mathrm{dm}^{3} \mathrm{~mol}^{-1} \mathrm{~s}^{-1}\right)$ for $i-\mathrm{X}=$} & \multirow[b]{2}{*}{$4-\mathrm{Br}$} \\
\hline & & $\mathrm{H}$ & $4-\mathrm{CH}_{3}$ & $4-\mathrm{C}_{2} \mathrm{H}_{5}$ & $4-\mathrm{F}$ & $4-\mathrm{Cl}$ & \\
\hline \multirow[t]{4}{*}{ Fru } & 288 & $3 \cdot 3$ & $2 \cdot 5$ & $3 \cdot 3$ & $3 \cdot 3$ & $5 \cdot 8$ & $4 \cdot 5$ \\
\hline & 293 & $10 \cdot 0$ & $8 \cdot 0$ & $7 \cdot 7$ & $7 \cdot 7$ & $10 \cdot 5$ & $10 \cdot 0$ \\
\hline & 298 & $16 \cdot 5$ & $15 \cdot 5$ & $11 \cdot 1$ & $16 \cdot 6$ & $18 \cdot 1$ & $16 \cdot 6$ \\
\hline & 303 & $25 \cdot 0$ & $23 \cdot 0$ & $20 \cdot 1$ & $23 \cdot 0$ & $33 \cdot 0$ & $28 \cdot 5$ \\
\hline \multirow[t]{4}{*}{ Glu } & 298 & $3 \cdot 5$ & $3 \cdot 2$ & $3 \cdot 2$ & $3 \cdot 6$ & $4 \cdot 5$ & $4 \cdot 2$ \\
\hline & 303 & $5 \cdot 0$ & $4 \cdot \overline{5}$ & $4 \cdot \overline{5}$ & $6 \cdot 2$ & $7 \cdot 1$ & $6 \cdot \overline{6}$ \\
\hline & 308 & $10 \cdot 1$ & $8 \cdot 3$ & $7 \cdot 2$ & $10 \cdot 0$ & $12 \cdot 5$ & $12 \cdot 5$ \\
\hline & 313 & $17 \cdot 6$ & $15 \cdot 5$ & $16 \cdot 6$ & $20 \cdot 1$ & $22 \cdot 0$ & $21 \cdot 5$ \\
\hline \multicolumn{8}{|c|}{$10^{-1} K_{l}\left(\mathrm{dm}^{3} \mathrm{~mol}^{-1} \mathrm{~s}^{-1}\right)$} \\
\hline \multirow[t]{4}{*}{ Fru } & 288 & $3 \cdot 5$ & $3 \cdot 4$ & $3 \cdot 3$ & $3 \cdot 2$ & $3 \cdot 0$ & $3 \cdot 0$ \\
\hline & 293 & $4 \cdot 8$ & $3 \cdot 0$ & $4 \cdot 6$ & $3 \cdot 6$ & $5 \cdot 8$ & $3 \cdot 4$ \\
\hline & 298 & $6 \cdot 6$ & $4 \cdot 2$ & $4 \cdot 0$ & $4 \cdot 0$ & $6 \cdot 3$ & $3 \cdot 6$ \\
\hline & 303 & $6 \cdot 6$ & $3 \cdot 5$ & $4 \cdot 5$ & $4 \cdot 0$ & $5 \cdot 6$ & $4 \cdot 0$ \\
\hline \multirow[t]{4}{*}{ Glu } & 298 & $3 \cdot 8$ & $4 \cdot 4$ & $3 \cdot 5$ & $3 \cdot 8$ & $3 \cdot 7$ & $4 \cdot 7$ \\
\hline & 303 & $4 \cdot 5$ & $4 \cdot 6$ & $4 \cdot 0$ & $4 \cdot 0$ & $4 \cdot 2$ & 4.5 \\
\hline & 308 & $5 \cdot 2$ & $4 \cdot 5$ & $4 \cdot 7$ & $3 \cdot 7$ & $3 \cdot 8$ & $4 \cdot 5$ \\
\hline & 313 & $5 \cdot 0$ & $5 \cdot 5$ & $4 \cdot 0$ & $4 \cdot 0$ & $5 \cdot 6$ & $5 \cdot 0$ \\
\hline
\end{tabular}

was calculated from the intercept of the plot by inserting $\left[\mathrm{OH}^{-}\right]$. The equilibrium constant $\left(K_{1}\right)$ was calculated from the ratio of intercept to the slope of the plot (table 3), assuming that $1>K_{1}\left[\mathrm{OH}^{-}\right]$. Further, the values of $k_{2}$ were calculated at different temperatures by varying [substrate] at each temperature (table 3 ). The activation parameters corresponding to $k_{2}$ have also been computed from the plots of $\log k_{2}$ versus $1 / T$ and $\log \left(k_{2} / T\right)$ versus $1 / T$ (table 4 ).

Applicability of the Hammett equation ${ }^{11}$ has also been tested for the oxidations of both fructose and glucose by all the oxidants. The plots of $\log k_{2}$ versus $\sigma p$ gave the following correlations for Fru and Glu oxidations.

$$
\begin{aligned}
& \log k_{2}=-6 \cdot 05+0 \cdot 316 \sigma p(r=0 \cdot 88)(\mathrm{Fru}), \\
& \log k_{2}=-6 \cdot 29+0 \cdot 515 \sigma p(r=0 \cdot 95)(\mathrm{Glu}) .
\end{aligned}
$$

Enthalpies and free energies of activations for the oxidations of D-fructose and D-glucose by all the Nbromobenzenesulphonamides have been correlated. Plots of $\Delta H^{\neq}$versus $\Delta S^{\neq}$gave better correlations with isokinetic temperatures of 321 and $309 \mathrm{~K}$ for fructose and glucose oxidations respectively.

$$
\begin{aligned}
& \Delta H^{\neq}=107 \cdot 3+0 \cdot 321 \Delta S^{\neq}(r=0.99)(\mathrm{Fru}), \\
& \Delta H^{\neq}=111 \cdot 0+0 \cdot 309 \Delta S^{\neq}(r=0.99)(\mathrm{Glu}) .
\end{aligned}
$$

Further, to see the effect of substitution in the oxidants on the energy of activation, $E_{a}$ values of substituted N-bromo-arylsulphonamides were optimised with reference to $\log A$ of the parent oxidant, the sodium salt of $\mathrm{N}$-bromo-benzenesulphonamide through the equation, $E_{a}=2.303 R T \quad(\log A-$ $\left.\log k_{\mathrm{obs}}\right)$. The energies of activation for the oxidation of either D-fructose or D-glucose by the oxidants with electron-releasing groups in the benzene ring are slightly higher than that of the parent oxidant (table 4 ), while the $E_{a}$ values are a little lower with the oxidants with electron-withdrawing groups in the benzene ring. Enthalpies of activations have the same trend. Similarly, $\log A$ values were optimised corresponding to $E_{a}$ of the parent oxidant for both the fructose and glucose oxidations, through the equation, $\log A=\log k_{\text {obs }}+E_{a} / 2 \cdot 303 R T$ (table 4). $\log A$ values are slightly higher for oxidants with electron-withdrawing groups in the benzene ring, while the effect of electron-releasing groups on $\log A$ is negligible. The free energies of activation 


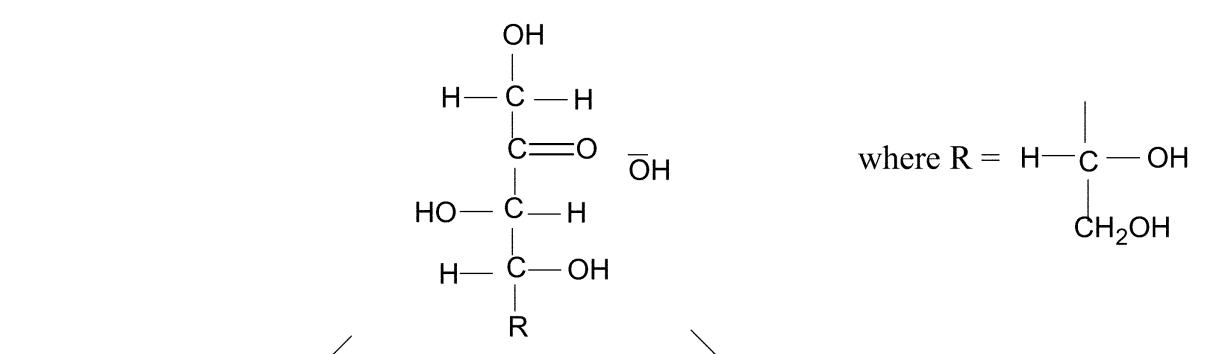<smiles>[R]C(O)C(O)C([O-])=C([O-])O</smiles><smiles>[R]C(O)C(O)=C([O-])C([2H])O</smiles>

$+\mathrm{HOH}_{\downarrow}-2 \mathrm{OH}^{-}$

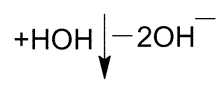<smiles>[R]C(O)C(O)/C(=C/O)OBr</smiles><smiles>[R]C(O)C(O)=C(OBr)C([2H])O</smiles>
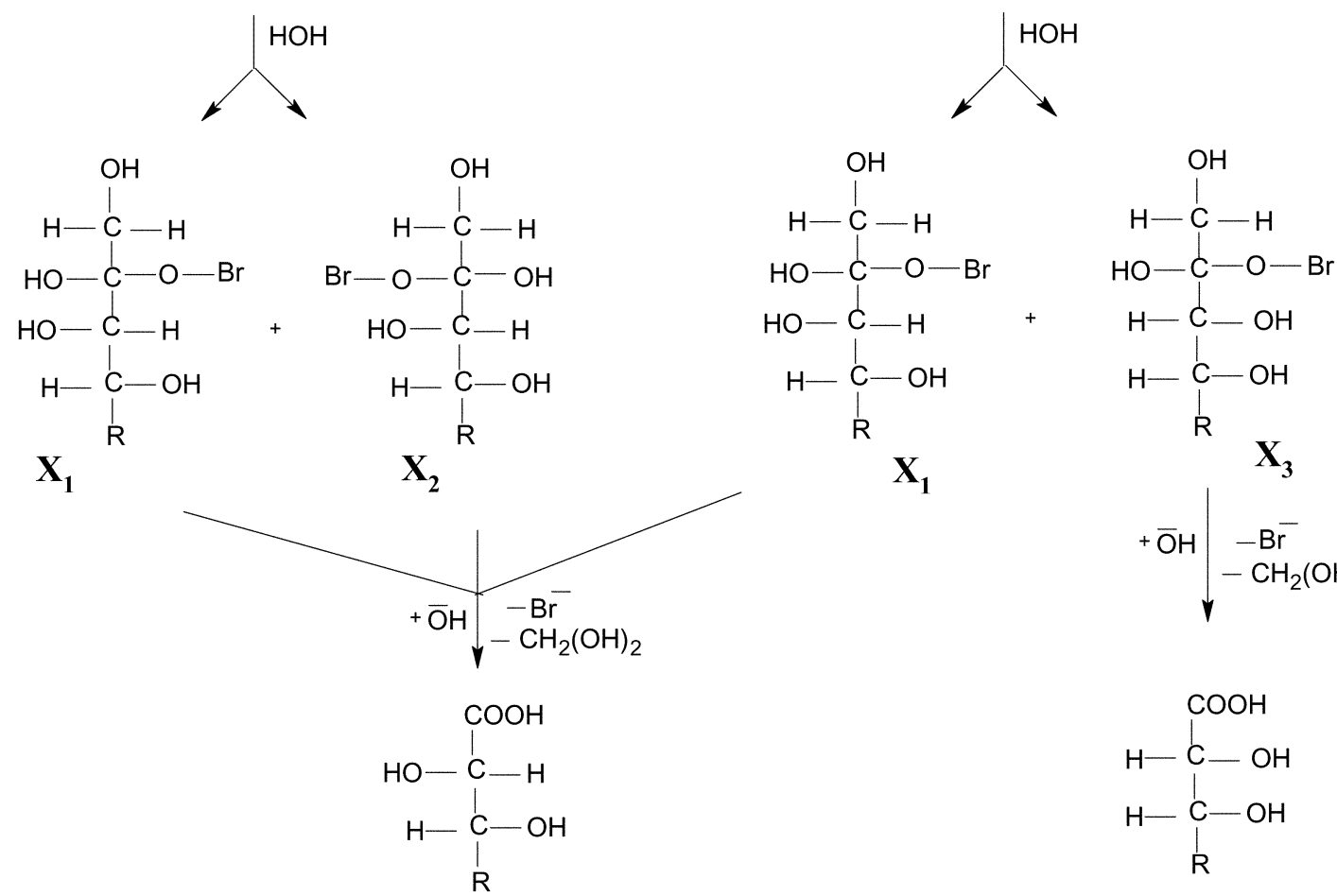

Arabinonic acid

Ribonic acid

Scheme 2. (Continued on facing page) 
<smiles>[R]C(O)[C@@H](O)[C@@H](O[Hg])[C@H]([2H])O</smiles><smiles>[R]C(O)C(O[Hg])C(O)(O)C([R])O</smiles><smiles>[R]C(O)C(O)C(O)(OBr)C([R])O</smiles>

$\mathrm{X}_{1}$

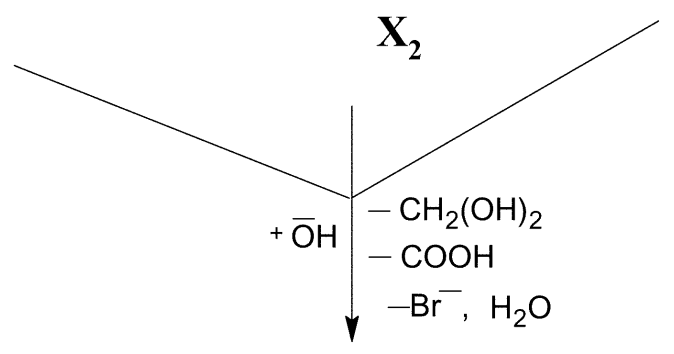

$\mathbf{X}_{3}$<smiles>[R]C(O)C=O</smiles>

Erythrose $\overline{\mathrm{OBr}}, \mathrm{H}_{2} \mathrm{O} \downarrow-\mathrm{OH}^{-}$<smiles>[R]C(O)C(O)OBr</smiles>

$$
+\overline{\mathrm{O}} \mathrm{H}_{\downarrow}-\mathrm{Br}, \mathrm{H}_{2} \mathrm{O}
$$<smiles>[R]C(O)C(=O)O</smiles><smiles>O=C(O)C(O)C(O)CO</smiles>

Erythronic acid<smiles>OCC(O)C(O)C(O)OBr</smiles><smiles>O=CC(O)CO</smiles><smiles>OC(O)C(Br)(Br)Br</smiles><smiles>O=C(O)C(O)CO</smiles>
Glyceric acid

Scheme 2. (Continued from facing page) 
Table 4. Activation parameters for the oxidation of D-fructose and D-glucose by sodium salts of $\mathrm{N}$ bromo- $p$-substituted benzenesulphonamides, $i-\mathrm{X}-\mathrm{C}_{6} \mathrm{H}_{4} \mathrm{SO}_{2}(\mathrm{Na}) \mathrm{NBr} \cdot x \mathrm{H}_{2} \mathrm{O}$, in aqueous alkaline medium.

\begin{tabular}{|c|c|c|c|c|c|c|}
\hline \multirow[b]{2}{*}{ Activation parameters } & \multicolumn{6}{|c|}{$i-\mathrm{X}=$} \\
\hline & Parent & $4-\mathrm{CH}_{3}$ & $4-\mathrm{C}_{2} \mathrm{H}_{5}$ & $4-\mathrm{F}$ & $4-\mathrm{Cl}$ & $4-\mathrm{Br}$ \\
\hline \multicolumn{7}{|l|}{ D-Fructose oxidations } \\
\hline$E_{a}\left(\mathrm{~kJ} \mathrm{~mol}^{-1}\right)$ & $98 \cdot 5$ & $105 \cdot 1$ & $107 \cdot 2$ & $103 \cdot 0$ & $88 \cdot 1$ & $88 \cdot 4$ \\
\hline $\log A$ & $11 \cdot 5$ & $11 \cdot 0$ & $12 \cdot 9$ & $12 \cdot 2$ & $9 \cdot 7$ & $9 \cdot 7$ \\
\hline$\Delta H^{\neq}\left(\mathrm{kJ} \mathrm{mol}{ }^{-1}\right)$ & $89 \cdot 4$ & $99 \cdot 3$ & $97 \cdot 5$ & $100 \cdot 3$ & $84 \cdot 6$ & $88 \cdot 4$ \\
\hline$\Delta S^{\neq}\left(\mathrm{JK}^{-1} \mathrm{~mol}^{-1}\right)$ & $-54 \cdot 6$ & $-29 \cdot 6$ & $-29 \cdot 0$ & $-2 \cdot 3$ & $-70 \cdot 4$ & $-58 \cdot 9$ \\
\hline$\Delta G^{\neq}\left(\mathrm{kJ} \mathrm{mol}^{-1}\right)$ & $105 \cdot 4$ & $107 \cdot 9$ & $106 \cdot 0$ & $100 \cdot 9$ & $105 \cdot 2$ & $105 \cdot 6$ \\
\hline \multicolumn{7}{|c|}{ Optimised values with reference to $\log A$ value of the parent oxidant } \\
\hline$E_{a}\left(\mathrm{~kJ} \mathrm{~mol}^{-1}\right)$ & $98 \cdot 5$ & $99 \cdot 0$ & $98 \cdot 8$ & $98 \cdot 8$ & $98 \cdot 0$ & $98 \cdot 1$ \\
\hline$\Delta H^{\neq}\left(\mathrm{kJ} \mathrm{mol}{ }^{-1}\right)$ & $89 \cdot 4$ & $88 \cdot 5$ & $90 \cdot 0$ & $90 \cdot 0$ & $89 \cdot 2$ & $89 \cdot 3$ \\
\hline \multicolumn{7}{|c|}{ Optimised values with reference to $E_{a}$ value of the parent oxidant } \\
\hline $\log A$ & $11 \cdot 5$ & $11 \cdot 4$ & $11 \cdot 4$ & $11 \cdot 4$ & $11 \cdot 5$ & $11 \cdot 5$ \\
\hline$\Delta S^{\neq}\left(\mathrm{JK}^{-1} \mathrm{~mol}^{-1}\right)$ & $-54 \cdot 5$ & $-57 \cdot 5$ & $-56 \cdot 8$ & $-56 \cdot 7$ & $-54 \cdot 1$ & $-54 \cdot 5$ \\
\hline \multicolumn{7}{|l|}{ D-Glucose oxidations } \\
\hline$E_{a}\left(\mathrm{~kJ} \mathrm{~mol}^{-1}\right)$ & $103 \cdot 1$ & $114 \cdot 1$ & $114 \cdot 8$ & $93 \cdot 4$ & $86 \cdot 5$ & $85 \cdot 5$ \\
\hline $\log A$ & $11 \cdot 5$ & $13 \cdot 3$ & $13 \cdot 1$ & $9 \cdot 9$ & $8 \cdot 8$ & $8 \cdot 5$ \\
\hline$\Delta H^{\neq}\left(\mathrm{kJ} \mathrm{mol}{ }^{-1}\right)$ & $97 \cdot 8$ & $102 \cdot 0$ & $110 \cdot 2$ & $85 \cdot 5$ & $85 \cdot 1$ & $87 \cdot 1$ \\
\hline$\Delta S^{\neq}\left(\mathrm{JK}^{-1} \mathrm{~mol}^{-1}\right)$ & $-42 \cdot 8$ & $-29 \cdot 7$ & $-3 \cdot 1$ & $-86 \cdot 8$ & $-81 \cdot 3$ & $-76 \cdot 1$ \\
\hline$\Delta G^{\neq}\left(\mathrm{kJ} \mathrm{mol}^{-1}\right)$ & $110 \cdot 7$ & $118 \cdot 2$ & $111 \cdot 1$ & $111 \cdot 7$ & $109 \cdot 7$ & $110 \cdot 1$ \\
\hline \multicolumn{7}{|c|}{ Optimised values with reference to $\log A$ value of the parent oxidant } \\
\hline$E_{a}\left(\mathrm{~kJ} \mathrm{~mol}^{-1}\right)$ & $103 \cdot 2$ & $103 \cdot 5$ & $103 \cdot 5$ & $102 \cdot 7$ & $102 \cdot 4$ & $102 \cdot 5$ \\
\hline$\Delta H^{\ddagger}\left(\mathrm{kJ} \mathrm{mol}{ }^{-1}\right)$ & $97 \cdot 8$ & $98 \cdot 1$ & $98 \cdot 0$ & $97 \cdot 3$ & $96 \cdot 9$ & $97 \cdot 1$ \\
\hline \multicolumn{7}{|c|}{ Optimised values with reference to $E_{a}$ value of the parent oxidant } \\
\hline $\log A$ & $11 \cdot 5$ & $11 \cdot 4$ & $11 \cdot 4$ & $11 \cdot 5$ & $11 \cdot 6$ & $11 \cdot 5$ \\
\hline$\Delta S^{\neq}\left(\mathrm{JK}^{-1} \mathrm{~mol}^{-1}\right)$ & $-42 \cdot 8$ & $-43 \cdot 8$ & $-43 \cdot 7$ & $-41 \cdot 1$ & $-40 \cdot 0$ & $-40 \cdot 6$ \\
\hline
\end{tabular}

remain almost the same indicating the operation of similar mechanisms in all the cases.

A typical detailed mechanism of oxidation of fructose isomer by an oxidant is schematically shown in scheme 2.

\section{Conclusion}

Effective oxidising species of the oxidants employed in the present oxidations is $\mathrm{Br}^{+}$in different forms, released from the oxidant. The introduction of different substituents into the benzene ring of the oxidant was expected to affect its ability to release $\mathrm{Br}^{+}$ and hence its capacity to oxidise the substrate. It is evident from the rate data that neither electronreleasing groups such as $\mathrm{CH}_{3}, \mathrm{C}_{2} \mathrm{H}_{5}$ nor electronwithdrawing groups such as $\mathrm{Cl}, \mathrm{Br}$ influence the rates of oxidations. This is due to the zero-order dependence of rate on [NBSBS] and $\mathrm{OBr}^{-}$being the effective oxidising species.

\section{References}

1. Campbell M M and Johnson G 1978 Chem. Rev. 78 65

2. (a) Gowda B T and Mahadevappa D S 1983 Talanta 30 359; (b) Gowda B T and Mahadevappa D S 1983 J. Chem. Soc., Perkin Trans. 2 323; (c) Gowda B T, Sherigara B S and Mahadevappa D S 1986 Microchem. J. 34 103; (d) Gowda B T and Bhat J I 1987 Tetrahedron 43 2119; (e) Gowda B T and Rao R V 1988 J. Chem. Soc., Perkin Trans. 2 355; (f) Gowda B T and Sherigara B S 1989 Int. J. Chem. Kinet. 21 31; (g) Gowda B T and Ramachandra P $1989 \mathrm{~J}$. Chem. Soc., Perkin Trans. 2 1067; (h) Gowda B T, D'Souza J D and Bhat K R 2002 J. Indian Chem. Soc. 78 412; (i) Gowda B T and Kumar B H A 2003 Oxid. Commun. 26403 (j) Gowda B T, Jayalakshmi K L and Jyothi K 2003 Z. Naturforsch. B58 787; (k) 
Gowda B T and Shetty M 2004 J. Phys. Org. Chem. 17 848; (1) Gowda B T, Jyothi K and Damodara N 2005 Int. J. Chem. Kinet. 37 572; (m) Gowda B T and Usha K M 2003 Z. Naturforsch. A58 351; (n) Shetty M and Gowda B T 2004 Z. Naturforsch. B58 63

3. Agrawal M C and Upadhyay S K 1990 J. Sci. Ind. Res. 4913

4. Mahadevappa D S, Iyengar T A and Puttaswamy 1990 Carbohydr. Res. 204197

5. Rangappa K S, Swamy H M, Raghavendra M P and Gowda D C 1998 Carbohydr. Res. 307253

6. Morrison R T and Boyd R N 1992 Organic chemistry (New Delhi: Prentice-Hall of India)
7. Schaffer R 1980 in The carbohydrates (eds) W Pigman and D Horton (New York: Academic) vol 1A

8. Green J W 1980 in The carbohydrates (eds) W Pigman and D Horton (New York: Academic) vol. $1 \mathrm{~B}$

9. Pigman W and Anet E F L J 1972 in The carbohydrates: Chemistry and biochemistry (eds) W Pigman and D Horton (New York: Academic) vol 1A, p 165

10. Stahl E 1969 Thin layer chromatography: A laboratory handbook (New York: Springer).

11. Hammett L P 1970 Physical organic chemistry (Tokyo: McGraw-Hill) 